\title{
परामर्श का किशोरियों की स्वप्रभावकारिता पर प्रभाव का अध्ययन।
}

दीपक सिंह, गुंजन शर्मा एवं प्रज्ञा सिंह लोधी

\section{सारांश}

परामर्श एक प्रकार की सहयोगी प्रक्रिया है जिसमें परामर्शदाता, परामर्श प्राप्तकर्ता को उसके जीवन के महत्त्वपूर्ण पहलुओं से सम्बन्धित ज्ञान प्राप्त करने में सहायता प्रदान करता है। किशोरावस्था में किशोरियों को किशोरावस्था के अनुरूप होनें वाले विभिन्न प्रकार के परिर्तनों के साथ समायोजन करने के लिए विभिन्न प्रकार की मनोवैज्ञानिक गुणवत्ताओं की आवश्यकता होती है। इन्हीं में से एक आवश्यक मनोवैज्ञानिक क्षमता, स्वप्रभावकारिता को शोध के अन्तर्गत सम्मिलित किया गया है। जो व्यक्ति की किसी चुनौतीपूर्ण परिसिथित या कार्य का सामना करने की समय-सीमा से सम्बन्धित होती है। प्रस्तुत शोध का उद्धेश्य परामर्श का किशोरियों की स्वप्रभावकारिता पर पडने वाले प्रभाव का अध्ययन करना है। इस अध्ययन में प्रयोगात्मक एंव नियन्त्रित समूह अभिकल्प का प्रयोग किया गया है। अध्ययन हेतु आकस्मिक प्रतिचयन विधि के द्वारा श्री राम कॉलेज मुजफ्फरनगर उ०प्र० से 16 से 18 वर्ष की 100 छात्राओं का चयन किया गया। जिनमें से 50 छात्राओं को प्रयोगात्मक समूह तथा 50 छात्राओं को नियन्त्रित समूह में रखा गया। प्रयोगात्मक समूह में सम्मिलित किशोरियों को 3 माह तक सप्ताह में एक दिन सामूहिक रूप से, तथा सप्ताह में एक दिन आवश्यकतानुसार व्यक्तिगत रूप से, 30 मिनट के लिए परामर्श प्रदान किया गया। स्वप्रभावकारिता मापनी के द्वारा आंकडो का संग्रहण किया गया। सांख्यिकीय विश्लेषण हेतु एस० पी० एस० एस० वर्जन 18 द्वारा अनोवा परीक्षण का उपयोग किया गया। अध्ययन से प्राप्त परिणामों से यह स्पष्ट होता है कि परामर्श का किशोरियों की स्वप्रभावकारिता पर सकारात्मक प्रभाव पडता है।

कूट शब्द- परामर्श, किशोरियॉ एवं स्वप्रभावकारिता।

परामर्श एक द्विपक्षीय प्रकिया है, जिसमें परामर्शकर्ता और परामर्श प्राप्तकर्ता भाग लेते हैं। लोगों को जीवन के सभी क्षेत्रों में अर्थप्रूण्ण सम्बन्धों की आवश्यकता होती है, और बहुत से लोगों को तो इन्हीं सम्बन्धों के आधार पर जीवन के महत्त्व और उद्देश्य से सम्बन्धित ज्ञान प्राप्त होता है। इसलिए परामर्श एक प्रकार की सहयोगी प्रक्रिया है जिसमे परामर्शदाता, परामर्श प्राप्तकर्ता को उसके जीवन के महत्त्वपूर्ण पहलुओं से सम्बन्धित ज्ञान प्राप्त करने में सहायता प्रदान करता है। किशोरावस्था में किशोर-किशोरियों में बहुत से परिवर्तन आते हैं। यह परिवर्तन सकारात्मक एवं नकारात्मक दोनों प्रकार के हो सकते हैं। नकारात्मक होने पर उनमें चिन्ता, निराशा तथा शक्ति ह्वास जैसी समस्याएँ उत्पन्न होने लगती है। अतः इस अवस्था में निर्देशन तथा परामर्श सेवा ज्यादा आवश्यक होती है। जिससे वें अपनी परेशानियों को समझ सकें तथा विद्यालय अथवा कॉलेज में अच्छी तरह समायोजित हो सकें।

शैक्षिक निर्देशन एवं परामर्श" नामक पुस्तक में रॉय ने उल्लेख किया गया है कि वर्तमान समय में समाज के जटिल स्वरूप के अनुरूप तीव्र गति से परिवर्तित हो रही आवश्यकताओं को परम्परागत शिक्षा के द्वारा पूर्ण नहीं किया जा सकता है। अतः समाज में व्यक्तिगत एवं सम्बन्धित पहलुओं के समायोजन के लिए विभिन्न व्यवसायिक प्रशिक्षण एंव शैक्षिक कार्यक्रम अत्यन्त आवश्यक है। इन सभी के लिए निर्देशन आवश्यक सूचनाएं प्रदान करता है (Rao, 1982)। मनोवैज्ञानिकों ने निर्देशन तथा परामर्श प्रोग्राम एजुकेशनल सिस्टम का एक अभिन्न हिस्सा माना है। जो इस उद्देश्य से संरचित किया जाता है, जिससे विद्यार्थियो
का विकास हो सके। राष्ट्रीय प्रोग्राम एवं अध्ययन के अनुसार बहुत से मानसिक स्वास्थ्य विशेषज्ञ जहाँ किसी मानसिक समस्या के लिए औषधियों के उपयोग से समस्या को वहीं स्थिर कर देते हैं, वहीं दूसरी ओर मनोश्चिकित्सक द्वारा प्रदान किया गया परामर्श व्यक्ति को समायोजन युक्तियों के साथ आत्मनियमन करना भी सिखाता है, जो कि औषधि की अपेक्षा लम्बे समय तक के लिए प्रभावी एवं व्यावहारिक विधि है। इसलिए यदि कोई भी बच्चा या किशोर किसी मानसिक समस्या के लिए चिकित्सक द्वारा औषध उपयोग कर रहा है, तो अवश्य ही उन्हे परामर्श हेतु मनोश्चिकित्सक के पास भी ले जाना चाहिए (National Registry of Evidence-Based Program and Practices, 2014)।

किरबी एवं सहयोगियों के अनुसार निर्देशन तथा परामर्श के प्रभाव के अध्ययन से प्राप्त निष्कर्षों के आधार पर मनोवैज्ञानिकों ने यह सुझाव प्रस्तुत किया है कि विद्यालय एक ऐसा स्थान होता हैं, जहाँ एक साथ अधिक मात्रा में छात्र-छात्राएँ उपलब्ध होते हैं, साथ ही ये छात्र-छात्राएँ अपना अधिकांश समय विद्यालय में व्यतीत करते हैं, तथा विद्यालय का शैक्षिक एवं सामाजिक वातावरण भी विद्यार्थियों के भावनात्मक तथा सामाजिक विकास में महत्त्वपूर्ण भूमिका निभाता है; इसलिए विद्यार्थियों के मानसिक-भावनात्मक एवं व्यक्तित्व विकास के लिए विद्यालयो में एसे कार्यक्रम आयोजित किए जाने चाहिए, जिनसे विकास के उद्देश्य की पूर्ति हो सके (Kirby et al., 2006)। कैरी एवं सहयोगियो के अनुसार अन्य अध्ययन से प्राप्त परिणामों के आधार पर मनोवैज्ञानिकों के समूह ने 
परामर्श विधि के लाभो को देखते हुए यह सुझाव दिए कि परामर्श विधि छात्रो के व्यक्तित्व विकास में प्रभावी भूमिका निभा सकती है, इसके लिए आवश्यक हैं कि परामर्श सेवा का लम्बे समय तक उपयोग किया जाये; जिससे छात्रो के शैक्षिक अधिगम परिणामों में भी पर्याप्त रूप से प्रभाव पड़े (Kari et al., 2015)।

शोध में सम्मिलित आश्रित चर स्वप्रभावकारिता को परिभाषित करते हुए स्वप्रभावकारिता सम्प्रत्यय के प्रतिपादक बैण्डुरा उल्लेख करते है कि स्वप्रभावकारिता व्यक्ति के द्वारा दिये गये लक्ष्य के प्रति कार्य प्रदर्शन करने की व्यक्तिगत योग्यता के प्रति विश्वास से सम्बन्धित होती है। यह व्यक्ति के व्यवहार तथा व्यवहार परिवर्तन के बीच मध्यस्थताकारी भूमिका निभाती है (Bandura, 1977)। स्वप्रभावकारिता व्यक्ति की अपनी क्षमताओं पर विश्वास से सम्बन्धित है, जो उसे किसी लक्ष्य की प्राप्ति या कार्य को पूरा करने की ताकत प्रदान करता है। उदाहरणार्थस्वप्रभावकारिता प्रत्यक्ष रूप से व्यक्ति की किसी चुनौतीपूर्ण परिस्थिति या कार्य का सामना करने की समय-सीमा से सम्बन्धित होती है- जैसे मैं अपना कार्य इस निर्धारित समय सीमा से पूर्व सम्पादित कर सकता-सकती हूँ। उच्च एवं निम्न स्तर की स्वप्रभावकारिता यह निर्धारित करने में महत्त्वपूर्ण भूमिका निभाती है कि व्यक्ति किसी चुनौतीपूर्ण कार्य को करना स्वीकार करता है या उसे असम्भव मानकर छोड़ देता है। क्योंकि स्वप्रभावकारिता का अभिप्रेरणा तथा कार्य प्रदर्शन में सकारात्मक सहसम्बन्ध होता है। उच्च स्वप्रभावकारिता उच्च अभिप्रेरणा तथा उच्च स्तरीय प्रदर्शन के साथ मजबूती से सहसम्बन्धित है (Cherian and Jackob, 2013)।

बैण्डुरा के अनुसार स्वप्रभावकारिता के सैंद्धान्तिक सम्प्रत्यय के अनुसार व्यक्ति अपने विचार प्रक्रम के द्वारा अपनी स्व प्रभावकारिता को बढ़ा या घटा सकता है। इसका अभिप्राय यह है कि हम अपने विचारों में अपनी सामर्थ्यों को लेकर जैसी धारणा विकसित कर लेते हैं, हमारी अपनी सामर्थ्य हमें उतनी ही प्रतीत होती है, जिस स्तर की हमारी व्यक्तिगत धारणा होती हैं (Bandura, 1986)। सोलियमनी एवं उनके सहयोगियों के अनुसार स्वप्रभावकारिता मानसिक स्वास्थ्य के लिए आधारभूत तत्व का कार्य करता है तथा व्यक्तित्व में उत्पन्न हो सकने वाले अनेक मनोवैज्ञानिक रोगों से बचाव में पर्याप्त प्रभावकारी भूमिका निभाता है (Soleimani et al., 2013)। पिखाफी ने अपने अध्ययन में स्वप्रभावकारिता तथा मानसिक स्वास्थ्य में अर्थपूर्ण सहसम्बन्ध पाया (Pirkhaefi, 2010)। डोन्चे एवं उनके सहयोगियों के अनुसार उच्च स्वप्रभावकारिता का आत्म-समायोजन तथा स्वास्थ्य व्यक्तित्व शीलगुणों के साथ सकारात्मक सहसम्बन्ध होता है (Donche et al., 2014)।

बार्जोग्वारी के अनुसार स्व्रभावकारिता तनाव के लक्षणों को कम करने में महत्त्वपूर्ण मध्यस्थ की भूमिका निभाती है (Bazorgvari, 2012)। किम ने अपने अध्ययन के आधार पर यह तथ्य प्रस्तुत किया कि व्यक्ति यदि तेजी से अपनी स्वप्रभावकारिता में वृद्धि करता हैं, तो इससे उसके चिन्ता एवं विषाद के स्तर में कमी आती है (Kim, 2003)। मोस्लेन पार्टो ने किशोरों पर किए गए अध्ययन में (428 किशोर,
486 किशोरियों) हाईस्कल स्तर के छात्रों के स्वप्रभावकारिता, मानसिक स्वास्थ्य तथा समस्या समाधान में पारस्परिक सम्बन्धों का अध्ययन किया गया। जिसमें यह पाया गया कि स्वप्रभावकारिता तथा समस्या समाधान योग्यता, मानसिक स्वास्थ्य को प्रत्यक्ष या अप्रत्यक्ष रूप से प्रभावित करते हैं, तथा मुखरता का गुण मानसिक स्वास्थ्य के साथ स्वप्रभावकारिता तथा समस्या समाधान में मध्यस्थताकारी भूमिका निभाता है (Parto, 2011)।

गोपोलन्ग मैटासरी ने अपने अध्ययन में 100 विद्यार्थियों की स्वप्रभावकारिता तथा आत्मशक्ति का शैक्षिक प्रदर्शन पर प्रभाव का अध्ययन किया। जिसमें यह परिणाम प्राप्त हुए कि स्वप्रभावकारिता तथा आत्मशक्ति का शैक्षिक प्रदर्शन से पर्याप्त सार्थक सहसम्बन्ध होता हैं। इनके अध्ययन में सम्मिलित $98 \%$ विद्यार्थियों ने यह बताया कि यदि वे चाहते तो वे और अधिक अच्छे ग्रेड प्राप्त कर सकते थे (Gopolang, 2014)। गस्टियाना ने स्वप्रभावकारिता, आत्मशक्ति, तथा उपलब्धि अभिप्रेरणा का; भाषा अधिगम व अभिव्यक्ति पर बोलने की चिन्ता पर प्रभाव के अध्ययन में यह पाया गया, कि छात्रों की आत्मशक्ति, स्वप्रभावकारिता तथा उपलब्धि अभिप्रेरणा तीनों ही सार्थक रूप से भाषा अधिगम एवं अभिव्यक्ति से जुड़ी चिन्ता को प्रभावित करती है (Mettasari, 2013)। मौली द्वारा किए गए अध्ययन में शोधकर्ता ने रचनात्मक स्वप्रभावकारिता, रचनात्मक आत्मशक्ति तथा रचनात्मकता का कलावर्ग के छात्रों पर सहसम्बन्धात्मक अध्ययन किया। जिसमें यह पाया गया कि कलाकार छात्रों में रचनात्मकता का रचनात्मक स्वप्रभावकारिता तथा रचनात्मक आत्मशक्ति के साथ घनिष्ठ रूप से सकारात्मक सहसम्बन्ध होता है (Spardello, 2012)।

\section{अनुसंधान का उद्देश्य}

प्रस्तुत शोध का उद्धेश्य परामर्श का किशोरियों की स्वप्रभावकारिता पर प्रभाव का अध्ययन करना है।

\section{अनुसंधान अभिकल्प}

प्रस्तुत अध्ययन में 'प्रयोगात्मक एवं नियन्त्रित समूह अभिकल्प' का उपयोग किया गया है। प्रयोगात्मक अप्रयोगात्मक समूह अभिकल्प के प्रयोग में शोधकर्ता ने अपने शोध प्रतिदर्श का चयन कर उन्हें दो भागो में विभाजित किया है। जिनमे एक समूह को प्रयोगात्मक परिस्थिति में रखा गया अर्थात् उन्हें एकल एवं सामुहिक रूप से परामर्शन दिया गया तथा दूसरे समूह को नियन्त्रित परिस्थिति में रखा गया अर्थात् उन्हें किसी प्रकार का परामर्शन नहीं दिया गया। अध्ययन से पूर्व व पश्चात् दोनो समूहों में आश्रित चर का मापन कर तुलना की गयी हैं।

\section{शोध परिकल्पना}

1- परामर्श लेने वाली एवं परामर्श न लेने वाली किशोरियों की स्वप्रभावकारिता में कोई सार्थक अन्तर नहीं होगा।

2- परामर्श लेने वाली किशोरियों एवं परामर्श न लेने वाली किशोरियों की स्वप्रभावकारिता पर समय अन्तराल का सार्थक प्रभाव नहीं होगा। 


\section{प्रतिदर्श चयन विधि एवं प्रतिदर्श}

प्रस्तुत अध्ययन हेतु 'आकस्मिक प्रतिचयन विधि' द्वारा श्री राम कॉलेज मुजफ्फरनगर उ०प्र० से 16 से 18 वर्ष की 100 छात्राओ का चयन किया गया।, जिनमें से 50 छात्राओ को प्रयोगात्मक समूह में तथा 50 छात्राओ को नियन्त्रित समूह में सम्मिलित किया गया है।

\section{समावेशन मापदण्ड}

प्रस्तुत शोध में 16 वर्ष से 18 वर्ष तक की किशोरियों को सम्मिलित किया जाएगा। केवल उन्हीं किशोरियों को सम्मिलित किया जाएगा जिनकी शैक्षणिक योग्यता कम से कम हाईस्कूल हो। जो शारीरिक मानसिक रूप से स्वस्थ हो।

\section{अपवर्जन मापदण्ड}

प्रस्तुत शोध में उन किशोरियों को सम्मिलित नहीं किया गया जो किसी प्रकार से शारीरिक व मानसिक रूप से अस्वस्थ हो अथवा कक्षा मे अनियमित हो।

\section{प्रयुक्त परीक्षण}

स्वप्रभावकारिता मापनी- प्रस्तुत शोध के अन्तर्गत स्वप्रभावकारिता को मापने के लिए Matthias Jerusalem तथा Ralf द्वारा निर्मित स्वप्रभावकारिता मापनी के English to Hindi version का (अंगेजी से हिन्दी संस्करण) जो कि सोनाली सूद द्वारा अनुवादित तथा भारतीय संस्कृति के अनुरूप मानकीकृत है का उपयोग किया गया है। इस परीक्षण
में कुल 10 प्रश्न है। अभी तक इस परीक्षण का 25 भाषाओं में अनुवाद हो चुका है, तथा हिन्दी संस्करण को शिमला के स्नातक स्तर के 398 (217 महिला, 181 पुरूष) छात्र-छात्राओं पर क्रियान्वित करके भारतीय परिप्रिक्ष्य में विशेषज्ञों के निर्देशन में मानक प्राप्त किए गए है।

\section{कार्य विधी}

प्रस्तुत अध्ययन हेतु आकस्मिक प्रतिचयन विधि द्वारा श्री राम कॉलेज मुजफ्फरनगर उ०प्र० से 16 से 18 वर्ष की 100 छात्राओं का चयन किया गया। जिनमें से 50 छात्राओं को प्रयोगात्मक समूह में तथा 50 छात्राओं को नियन्त्रित समूह में सम्मिलित किया गया है। शोध मे सम्मिलित प्रयोगात्मक समूह की किशोरियों को सप्ताह में एक दिन सामूहिक रूप से परामर्श प्रदान किया गया तथा आवश्यकतानुसार सप्ताह में एक दिन व्यक्तिगत रूप से परामर्श प्रदान किया गया। नियन्त्रित समूह की छात्राओं को किसी प्रकार का अभ्यास नहीं करवाया गया। स्वप्रभावकारिता मापनी द्वारा दोनो समूह की किशोरियों की स्वप्रभावकारिता का तीन चरणों- प्रयोग पूर्व अवस्था, 45 दिनों बाद मध्य अवस्था तथा 3 माह बाद अन्तिम अवस्था में मापन करके आंकडे संग्रह किये गये।

\section{सांख्यिकीय विश्लेषण}

प्रस्तुत शोध के परिणामो के सांख्यिकीय विश्लेषण हेतु एस पी एस एस वर्जन 18 के माध्यम से टी-परिक्षण एवं वन वे अनोवा परिक्षण का उपयोग किया गया है।

\section{शोध परिणाम}

1- परामर्श लेने वाली एवं परामर्श न लेने वाली किशोरियों की स्वप्रभावकारिता में कोई सार्थक अन्तर नहीं होगा।

\begin{tabular}{|l|c|c|c|c|l|l|c|}
\hline Group & $\mathbf{N}$ & $\begin{array}{l}\text { Mean* } \\
\text { (Gain } \\
\text { Scores })\end{array}$ & S.D. & SE $_{\mathbf{D}}$ & df & t-value & Level of sig. \\
\cline { 1 - 4 } Experimental & 50 & 14.76 & 3.84 & \multirow{2}{*}{0.57} & 98 & 16.16 & 0.01 \\
\hline Control & 50 & 0.82 & 0.91 & 0.57 \\
\hline
\end{tabular}

उपरोक्त सारिणी से यह स्पष्ट होता है कि प्रयोगात्मक समूह के gain score* ( पूर्व व अन्तिम परिक्षण के प्राप्ताकों के अन्तर) का मध्यमान व मानक विचलन क्रमशः $14.76 \pm 3.84$ तथा नियंत्रित समूह के gain score (पूर्व व अन्तिम परिक्षण के प्राप्तांको के अन्तर) का मध्यमान व मानक विचलन क्रमशः $0.82 \pm 0.91$ है। मानक त्रुटि विचलन 0.57 तथा $\mathrm{t}$ का मान 16.16 है, जो कि $98 \mathrm{df}$ के साथ टी-सारणी में 0.01 स्तर पर सार्थक है। इससे यह स्पष्ट होता है कि दोनो समूहों के मध्यमानों के बीच सार्थक अन्तर है तथा शून्य परिकल्पना 'परामर्श लेने वाली एवं परामर्श न लेने वाली किशोरियों की स्वप्रभावकारिता में कोई
अन्तर नहीं होगा' निरस्त की जाती है, और यह कहा जा सकता है कि परामर्श विधि के उपयोग का किशोरियों की स्वप्रभावकारिता पर सार्थक प्रभाव पडता है।

2- परामर्श लेने वाली किशोरियों एवं परामर्श न लेने वाली किशोरियों की स्वप्रभावकारिता पर समय अन्तराल का सार्थक प्रभाव नहीं होगा।

प्रस्तुत शोध में प्रायोगिक समूह पर परामर्श का स्वप्रभावकारिता पर पड़ने वाले प्रभाव के अध्ययन हेतु आश्रित चर - स्वपभावकारिता का मापन विभिन्न समयान्तरालों (अध्ययन से पूर्व, मध्य व अंतिम अवस्था में) किया 
सिंह, शर्मा एवं लोधी

गया था। इसी प्रकार नियंत्रित समूह का भी तीन समयान्तरालों में परिक्षण

किया गया। जिसका विश्लेषण रिपीटिड मेजर अनोवा (Repeated
Measure ANOVA with Geenhouse-Geisser correction) विधि द्वारा किया गया है। जिनके परिणाम इस प्रकार है-

Experimental Group: Descriptive Statistics

\begin{tabular}{|l|l|l|l|l|}
\hline Conditions & Tests & Mean & S.D. & N \\
\hline Conditions-1 & Pre-test & 20.84 & 4.54 & 50 \\
\hline Conditions-2 & Mid-test & 29.38 & 3.81 & 50 \\
\hline Conditions-3 & Post-test & 35.60 & 3.19 & 50 \\
\hline
\end{tabular}

Test of Within-Subjects Effects

\begin{tabular}{|l|l|l|l|l|l|l|}
\hline Source & Correction & $\begin{array}{l}\text { (Type III) Sum of } \\
\text { Squares }\end{array}$ & Df & $\begin{array}{l}\text { Mean } \\
\text { Square }\end{array}$ & F & Sig. \\
\hline Time & $\begin{array}{l}\text { Greenhouse- } \\
\text { Geisser }\end{array}$ & 25766.41 & 1.68 & 15335.47 & 232.847 & .000 \\
\hline $\begin{array}{l}\text { Error } \\
\text { (time) }\end{array}$ & $\begin{array}{l}\text { Greenhouse- } \\
\text { Geisser }\end{array}$ & 5422.253 & 82.32 & 65.861 & \\
\hline
\end{tabular}

Tests of Within-Subjects Effects तालिका से यह ज्ञात होता है कि प्रायोगिक समूह में परामर्श लेने वाली किशोरियों का विभिन्न समयान्तरालों पर स्वप्रभावकारिता के मध्यमानों के बीच सार्थक अन्तर $\mathrm{F}(1.68,82.32)=232.84, \mathrm{p}<0.000)$ है।

Pairwise comparisons

\begin{tabular}{|l|l|c|c|c|}
\hline (I) conditions & (J) conditions & Mean difference (I-J) & Std.Error & Sig. \\
\hline pre- test (1) & mid- test (2) & $-8.540^{*}$ & .516 & .000 \\
\hline pre- test (1) & post- test (3) & $-14.760^{*}$ & .626 & .000 \\
\hline Mid- test (2) & post- test (3) & $-6.220^{*}$ & .409 & .000 \\
\hline
\end{tabular}

Pairwise Comparisons हेतु Tukey Post Hoc Test के द्वारा गणना की गयी। जिससे यह ज्ञात होता है कि परामर्श लेने वाले समूह की किशोरियों की स्वप्रभावकारिता में परामर्श आरम्भ करने से पूर्व परिक्षण $(20.84 \pm 4.54)$ कि तुलना में मध्य परिक्षण $(29.38 \pm$ $3.81, \mathrm{P}=0.00)$ व पश्चात परिक्षण $(35.60 \pm 3.19, \mathrm{P}=0.00)$ तथा मध्य परिक्षण $(29.38 \pm 3.80, \mathrm{P}=0.00)$ कि तुलना में पश्चात
परिक्षण $(35.60 \pm 3.19, \mathrm{P}=0.00)$ के बीच साख्यिकीय रूप से सार्थक अन्तर है। अतः यह कहा जा सकता है कि परामर्श विधि के उपयोग का कम व अधिक दोनों समयावधि के अभ्यास का स्वप्रभावकारिता पर सार्थक प्रभाव पडता है तथा मध्यमान से यह भी स्पष्ट होता है कि समायावधि के अनुसार प्रभाव भी बढ़ता हैं।

अप्रयोगात्मक समूह की किशोरियों की स्वप्रभावकारिता के प्राप्तांकों का विभिन्न समयअन्तरालों में विश्लेषण-

Control Group: Descriptive Statistics

\begin{tabular}{|l|l|l|l|l|}
\hline Conditions & Tests & Mean & S.D. & N \\
\hline Conditions-1 & Pre-test & 28.600 & 5.12 & 50 \\
\hline Conditions-2 & Mid-test & 29.640 & 5.18 & 50 \\
\hline Conditions-3 & Post-test & 29.420 & 4.63 & 50 \\
\hline
\end{tabular}


Test of Within-Subjects Effects

\begin{tabular}{|l|l|l|l|l|l|l|}
\hline Source & \multicolumn{1}{|c|}{ Correction } & $\begin{array}{c}\text { (Type III) Sum of } \\
\text { Squares }\end{array}$ & \multicolumn{1}{|c|}{ Df } & $\begin{array}{c}\text { Mean } \\
\text { Square }\end{array}$ & F & Sig. \\
\hline Time & $\begin{array}{l}\text { Greenhouse- } \\
\text { Geisser }\end{array}$ & 30.04 & 1.90 & 15.79 & 2.08 & 0.13 \\
\hline $\begin{array}{l}\text { Error } \\
\text { (time) }\end{array}$ & $\begin{array}{l}\text { Greenhouse- } \\
\text { Geisser }\end{array}$ & 704.62 & 93.21 & 7.56 & \\
\hline
\end{tabular}

Tests of Within-Subjects Effects तालिका से यह ज्ञात होता है कि नियंत्रित समूह की किशोरियों का विभिन्न समयान्तरालों पर स्वप्रभावकारिता के मध्यमानों के बीच कोई सार्थक अन्तर नहीं है $(\mathrm{F}(1.90,93.7 .56)=2.08, \mathrm{P}=.132)$ है।

\section{Pairwise comparisons}

\begin{tabular}{|l|l|c|c|l|}
\hline (I) conditions & $(\mathbf{J})$ conditions & Mean difference (I-J) & Std.Error & Sig. \\
\hline pre- test (1) & mid- test (2) & -1.920 & 1.192 & .341 \\
\hline pre- test (1) & post- test (3) & -2.120 & 1.089 & .172 \\
\hline mid- test (2) & post- test (3) & -.200 & .761 & 1.000 \\
\hline
\end{tabular}

Pairwise Comparisons हेतु Tukey Post Hoc Test के द्वारा गणना की गयी। जिससे यह ज्ञात होता है कि नियंत्रित समूह की किशोरियों की स्वप्रभावकारिता में अध्ययन आरम्भ करने से पूर्व परिक्षण $(28.60 \pm 5.12)$ कि तुलना में मध्य परिक्षण $(29.64 \pm 5.18$, $\mathrm{P}=0.34)$ व पश्चात परिक्षण $(29.42 \pm 4.63, \mathrm{P}=0.17)$ तथा मध्य परिक्षण $(29.64 \pm 5.18)$ कि तुलना में पश्चात परिक्षण $(29.42 \pm 4.63, \mathrm{P}=1.00)$ के बीच साख्यिकीय रूप से कोई सार्थक अन्तर नहीं है।

\section{परिणामों की व्यख्या}

प्रस्तुत शोध के परिणामों के विश्लेषण से यह तथ्य प्राप्त होते है कि परामर्श विधि के उपयोग का किशोरियों की स्वप्रभावकारिता पर सकारात्मक प्रभाव पाया गया; तथा परामर्श लेने वाली और परामर्श न लेने वाली किशोरियों की स्वप्रभावकारिता में सांख्यिकी रूप से सार्थक अन्तर प्राप्त हुए। अतः परिणामों के आधार पर यह कहा जा सकता है कि परामर्श का किशोरियों की स्वप्रभावकारिता पर सकारात्मक प्रभाव पडता है; तथा 45 दिनों की तुलना में 90 दिनों तक परामर्श विधि का उपयोग किशोरियों की स्वप्रभावकारिता पर अधिक सार्थक प्रभाव डालता है; और परामर्श प्रक्रिया किशारावस्था में उत्पन्न होने वाली विभिन्न समस्याओं के समाधान एवं चुनौतियों का सामना करने में सहयोगी भूमिका निभाने में सक्षम प्रक्रिया है।

व्यक्ति द्वारा अपनी समस्याओं के समाधान तथा लक्ष्यों की पूर्ति उसकी स्वप्रभावकारिता पर निर्भर करती हैं। व्यक्ति की स्वप्रभावकारिता उसकी आत्मगत क्षमताओं पर विश्वास पर निर्भर करती है। बैण्डुरा व्यक्ति की स्वप्रभावकारिता के प्रति धारणा के आधार पर ही व्यक्ति की कार्य के
प्रति संकल्प बद्धता, प्रयास का स्तर, दृढ़ता तथा लचीलापन निर्भर करता है। अतः व्यक्ति के कार्य तथा आत्मप्रत्यक्षण में स्वप्रभावकारिता की अत्यधिक महत्त्वपूर्ण भूमिका होती है। परामर्श कार्य के द्वारा परामर्शदाता को परामर्शग्राही के व्यक्तित्व का समग्र रूप से मूल्यांकन करतें हुए उसके व्यक्तित्व की क्षमताओं की पहचान कराने, क्षमताओं का उपयोग करवाने तथा विकास करनें में सहयोगी के रूप में कार्य करना होता है (Bandura, 1986)। गोर ने अपने अध्ययन में परामर्श प्रक्रिया के प्रभावस्वरूप छात्रों की स्वप्रभावकारिता में सकारात्मक वृद्धि पाई (Gore, 2006)।

अमरनाथ एवं अर्थाना (2012) के अनुसार परामर्श प्रक्रिया की समस्त गतिविधियाँ व्यक्ति के स्वास्थ्य, पीड़ा, तनावग्रस्तता, उसकी अन्तर्निहित सामर्थ्यों की पूर्णसिद्धि, व्यक्ति के सम्पूर्णरूपेण एक प्रकार्यात्मक इकाई के रूप में कार्य करने में समुत्पन्न बाधाओं के निराकरण, वर्तमान समस्याओं के समाधान, भविष्य की समस्याओं के परिहार, व्यक्तित्व का विकास आदि से जुड़ी होती है। कैनथ ने एक अपने अध्ययन में सम्मिलित 240 सैकेन्डरी एक्कूल के छात्रों पर किए अध्ययन के आधार पर यह निष्कर्ष प्रदान किए कि किशोरों में आत्म-अवधारणा के विकास हेतु परामर्श व मार्गदर्शन अत्यन्त प्रभावी विधि हैं, जिससे शिक्षार्थियों के आत्म-सम्मान में वृद्धि के साथ अनुशासनहीनता के व्यवहार में भी कमी आती है; तथा इसका उनके शैक्षिक निष्पादन पर भी सकारात्मक प्रभाव पड़ता है (Kenneth, 2014)।

विद्यालयों में चलाए जाने वाले परामर्श कार्यक्रमों का स्वप्रभावकारिता के विकास में महत्त्व का वर्णन करते हुए बैरना एवं ब्रोट ने अपने अध्ययन के आधार पर बताया कि परामर्श कार्यक्रम विद्यार्थियों के समग्र उपलब्धि तथा स्वप्रभावकारिता के विकास में सहयोग प्रदान करते 
हैं। स्वप्रभावकारिता का विकास विभिन्न प्रकार के सामाजिक और संज्ञानात्मक सिद्धान्तों के नियमों के आधार पर होता है। इसलिए विभिन्न प्रकार की सामाजिक अन्त:क्रियाएं व्यक्ति की स्वप्रभावकारिता को प्रभावित करती है। इस तथ्य को ध्यान में रखते हुए मनोवैज्ञानिकों द्वारा निर्मित किए जाने वाले हस्तक्षेप कार्यक्रम तथा परामर्श प्रक्रियाओं का उपयोग लोगो की स्वप्रभावकारिता के विकास में सहयोगी भूमिका निभाते हैं (Barna and Brott, 2011)। बैरिन ने अपने अध्ययन में 72 परामर्श चिकित्सकों के अपनी परामर्श कौशल के प्रति स्वप्रभावकारिता का छात्र-छात्राओं के मानसिक स्वास्थ्य पर प्रभाव का अध्ययन किया। जिसके परिणाम में उन्होने पाया कि जिन चिकित्सकों ने अपने कार्यक्षेत्र इत्यादि में पर्याप्त कार्य अनुभव तथा शैक्षिक उपलब्धि होती हैं उनमें उनके परामर्श कार्य के प्रति उच्च स्वप्रभावकारिता पाई गई, जिसका उनके क्लाइंटस के मानसिक स्वास्थ्य पर सकारात्मक प्रभाव पाया गया (Schiele, 2013)।

परामर्श प्रक्रिया एक प्रकार की आत्मविकासप्रद प्रक्रिया है, जिसका मुख्य उद्द्रेश्य व्यक्ति को आत्मखोज, आत्मपहचान, आत्मज्ञान एवं आत्मनिर्भर बनाते हुए आत्मविकास करना होता है। शैक्षिक परिप्रेक्ष्य में एवं किशोरावस्था में हो रहे परिवर्तनो के साथ सामजस्य स्थापित करने में, उचित करियर विकल्प के चयन में, समायोजन सम्बन्धी समस्याओं से निबटने में, बेहतर अकादमिक प्रदर्शन में, सम्बन्धों के समायोजन में, परामर्श विधि सहयोगी भूमिका निभाती है। लम्बे समय तक परामर्श विधि के उपयोग से छात्रों में विद्यालय तथा अकादमिक कार्यों में बेहतर प्रदर्शन, सकारात्मक व्यवहार एवं सकारात्मक मनोवृत्ति एवं आत्मसम्मान को भी बढाया जा सकता है। ओसाइडो एवं आईयामू के अनुसार प्रत्येक विद्यालय में परामर्शदाता की अनिवार्य रूप से सेवा ली जानी चाहिए, जिससे कि बच्चों को सामाजिक रूप से समायोजित होना सिखाया जा सके (Osaedoh and Iyamu, 2012)।

\section{निष्कर्ष}

प्रस्तुत शोध से यह तथ्य प्राप्त होते है कि परामर्शदाता द्वारा परामर्श सम्बन्धों में विश्वसनीयता के सहयोग से प्रभावी सूचना प्रदान करके परामर्शग्राही की स्वप्रभावकारिता का विकास किया जा सकता है। इसके अलावा विभिन्न प्रकार की सामाजिक एवं संज्ञानात्मक अनुक्रियाएँ भी व्यक्ति की स्वप्रभावकारिता को प्रभावित करती हैं। परामर्शदाता द्वारा मॉडलिंग, अनुकरण ,संज्ञानात्मक तथा सामाजिक सिद्धान्तों की विधियों का उपयोग करके किशोरियों की स्वप्रभावकारिता में वृद्धि की गई जिसका किशोरियों के व्यक्तित्व के अन्य पहलुओं पर भी सकारात्मक प्रभाव पडा।

दीपक सिंह, पी-एच०डी०., सहायक प्राध्यापक, मनोविज्ञान विभाग, गुरूकुल कांगड़ी विश्वविद्यालय, हरिद्वार; गुंजन शर्मा, पी-एच०डी०, प्रज्ञा सिंह लोधी, पी-एच०डी०., सहायक प्राध्यापक, मनोविज्ञान विभाग देव संस्कृति विश्वविद्यालय, हरिद्वार।

\section{सन्दर्भ ग्रन्थ सूची}

अस्थाना, अमरनाथ एवं अस्थाना, मधु (2012). निर्देशन एवं परामर्शः सम्प्रत्यय क्षेत्र एवं उपागम, चतुर्थ संस्करण/नई दिल्ली- मोतीलाल बनारसीदास प्रकाशन।

Bandura, A. (1977). Self efficacy: Toward a unifying theory of behavioral change. Psychology Review, 84(2), 191-215.

Bandura, A. (1986). Social foundations of thought and action: A social cognitive theory. Englewood Cliffs, NJ: Prentice-Hall.

Barana, J. S. \& Brott, E. P. (2011). How important is personal/social development to acadmic achievement? The elementary school counselor's perspective. Professional School Counselling, 14(3). Retrieved from https://doi.org/10.1177/2156759X1101400308

Bozorgvari, S. (2012). The consideration of employers' selfefficiency and organizational commitment of the whole education organization of Khorasan-e-Razawi. Journal of Counseling and Development, 27, 237-248.

Cherian, J. \& Jacob, J. (2013). Impact of Self Efficacy on Motivation and Performance of Employees. International Journal of Business and Management, 8 (4), 114-129.

Donche, V., Van-Daal, T., \& Maeyer, S. (2014). The Impact of Personality, Goal Orientation and Self-Efficacy on Participation of High School Teachers in Learning Activities in the Workplace.Vocations and Learning, 7(1), 21-40.

Gopolang, M. (2014). Role of self-efficacy and self-esteem in academic performance. European Journal of Educational Sciences, $2(2), 8-22$.

Gore, P. A. (2006). Academic self- eficacy as a predictor of college outcomes: Two incremental validity studies. Journal of Career Assessment, 14, 92-115.

Kari, H., Lars, K. \& Gerd, H. L. (2015). The effects of reflective counseling on learning outcomes for undergraduate students in social education. Retrieved fromhttps://www.idunn.no/uniped/2015/02/the_effects_of_reflective_coun seling_on_learning_outcomes_f

Kenneth, O. O. (2014). Effectiveness of Guidance and Counseling Services on Adolescent Self- concept. International Journal of Human Resource Studies, 4(4), Retrieved fromhttp://dx.doi.org/10.5296/ijhrs.v4i4.6498. 
Kim, B. S. K., Li, L. C. \& Liang, C. T. H. (2002). Effects of Asian American client adherence to Asian cultural values, session goal, and counselor emphasis of client expression on career counseling process. Journal of Counseling Psychology, 49, 342-354.

Kirby, M. J. L. \& Keon, W. J. (2006). Out of the shadows at last: Transforming mental health, mental illness and addiction services in Canada. Ottowa, Ont: Standing Senate Committee on Social Affairs, Science and Technology, Canada.

Mettasari, G. (2013). Self-esteem, achievement motivation, self efficacy and student's anxiety in Speaking. Jurnal Pendidikan dan Pengajaran, $46(2), 163-173$

DOI: http://dx.doi.org/10.23887/jppundiksha.v46i2\%20Juli.2767

National registry of evidence-based program and practices (2014). Substance and Mental Health Services Administration: SAMHSA. Retrieved from-http://www.samhsa.gov/nrepp

Osaedoh, G. 1. \& Iyamu, F. I. (2012). social life adjustment and academic achievement of adolescents in edo state : implication for counseling: Ozean Journal of Applied Science, 5 (2),159-167.

Parto, M. (2011). Problem solving, self- efficacy, and mental health in adolescents: Assessing the mediating role of assertiveness. Procedia - Social and Behavioral Sciences, 30, 644-648. https://doi.org/10.1016/j.sbspro.2011.10.125
Pirkhaefi, Alireza-Barhabli, Ahmad-Delawar, Ali-Eskandari, H., (2010). "The consideration of structural relationship of creativity, self-efficiency and facing method with mental health". Ravanshenasi tarbiyati magazine, 4 (17), 87-106

Roe, S. Narayna, (1982). Counselling Psychology. New Delhi: Tata McGraw Hill Publishing Co.ltd.

Schiele, B. E. (2013). The Importance of Counseling Self-Efficacy In School Mental Health. University of South Carolina - Columbia: Theses and Dissertations.

Soleimani, E. \& Howeida, R. (2013). The consideration of selfefficiency concept in Boundora`s theory of social cognition. Nowavarihaye amoozesh quarterly journal, 63, 91-97.

Spardello, M. E. S. (2012). Creativity Beliefs of Elementary Students: Self efficacy, Self-esteem and Beliefs in Between. Thesis, Georgia State University. Retrieved fromhttp://scholarworks.gsu.edu/art design theses/123. 